\title{
The effect of temperature on the developmental rates of seedling emergence and leaf-unfolding in two dwarf bamboo species
}

\author{
Shuyan Lin ${ }^{1}\left(\right.$ Lijuan Shao $^{1} \cdot$ Cang Hui ${ }^{2} \cdot$ Hardev S. Sandhu ${ }^{3} \cdot$ Tingting Fan $^{1} \cdot$ Li Zhang $^{1} \cdot$ Fang Li $^{1} \cdot$ Yulong Ding $^{1}$. \\ Peijian Shi ${ }^{1}$
}

Received: 19 September 2017 / Accepted: 25 January 2018 / Published online: 1 February 2018

○) Springer-Verlag GmbH Germany, part of Springer Nature 2018

\begin{abstract}
Key message The mean and variance of developmental rates of bamboos at different temperatures follow a power law. The rate isomorphy hypothesis, demonstrated in insects and mites, does not hold in bamboos.

Abstract The developmental time of plants and poikilotherms can be significantly affected by temperature. Developmental rate (i.e. the reciprocal of developmental time) of arthropods and germination rate of some plant seeds have been demonstrated to follow a linear function with temperature. The rate isomorphy hypothesis in entomology suggests a lower developmental threshold below which development of all life stages terminates. If this hypothesis also holds for plants, the estimated lower threshold for one development stage could be used for predicting thresholds of other stages. Here, we tested this hypothesis to compare the developmental time of seedling emergence and the time from seedling emergence to the unfolding of the third leaf in two bamboo species. We used five constant thermal environments from 18.5 to $28.5^{\circ} \mathrm{C}$ with an increment of $2.5^{\circ} \mathrm{C}$. Both species showed a linear relationship between temperature and developmental rate, with the mean and variance of developmental rates following a power law. Using the bootstrap percentile method, we showed that the isomorphy hypothesis does not hold for both species. The effect of temperature on the survival rate at the time of seedling emergence differed significantly between the two species.
\end{abstract}

Keywords Bootstrap $\cdot$ Development $\cdot$ Lower developmental threshold $\cdot$ Rate isomorphy $\cdot$ Weighted least squares

Communicated by R. Guy.

Electronic supplementary material The online version of this article (https://doi.org/10.1007/s00468-018-1669-0) contains supplementary material, which is available to authorized users.

Peijian Shi

peijianshi@gmail.com

1 Co-Innovation Centre for Sustainable Forestry in Southern China, Bamboo Research Institute, Nanjing Forestry University, 159 Longpan Road, Xuanwu District, Nanjing 210037, China

2 Department of Mathematical Sciences, Centre for Invasion Biology, Stellenbosch University, and African Institute for Mathematical Sciences, Matieland 7602, South Africa

3 Everglades Research and Education Center, University of Florida, 3200 E. Palm Beach Road, Belle Glade, FL 33430, USA

\section{Introduction}

Temperature is generally considered as a crucial factor impacting the growth and development of poikilotherms (Sharpe and DeMichele 1977; Shi et al. 2013; Quinn 2017a, b). Poikilotherms usually experience different developmental stages with slight or drastic changes in form at each stage. The time required for completing a particular stage is measured as developmental time or developmental duration (Uvarov 1931; Campbell et al. 1974). Previous studies have demonstrated significant temperature effect on developmental time of arthropods (Wagner et al. 1984; Li and Jackson 1996; Quinn et al. 2013; Shi et al. 2016a, 2017d; Mirhosseini et al. 2017; Quinn 2017a; Rebaudo et al. 2017; Yamamoto et al. 2017). However, the effect of temperature on developmental rate (the reciprocal of developmental time, which is often used for measuring the percentage of the development in unit time) varies over different temperature ranges or zones. At lower temperatures, developmental rate increases approximately exponentially with increase 
in temperature; at moderate temperatures, developmental rate is approximately a linear function of temperature; at high temperatures, developmental rate dramatically drops with increase in temperature beyond a critical temperature associated with the maximal developmental rate (Uvarov 1931; Campbell et al. 1974; Wagner et al. 1984; Shi et al. 2016a, 2017d). Such a thermal developmental curve over these three thermal regions is usually assessed in controlled environments with a constant temperature. The curve can be used for predicting, for instance, the occurrence date of a particular phenological event of arthropods by accumulating the daily developmental rates for full development from a starting date (Wagner et al. 1984; Ungerer et al. 1999; Ikemoto and Egami 2013; Shi et al. 2017a). If the temperaturedependent developmental rate curve is also applicable to plants, we can predict the occurrence date of a particular phenological event in plants. For instance, Shi et al. (2017b) used the accumulative developmental progress method based on the Arrhenius' equation (an exponential equation describing the effect of absolute temperature on developmental rate in the low- and mid-temperature zones) to predict the first hatching date of bamboo locust (Ceracris kiangsu Tsai) in spring. This method can also be used to predict the first flowering date of Japanese cherry tree (Prunus yedoensis Matsum) in early spring (Shi et al. 2017a). In theory, the accumulative developmental progress method combined with a nonlinear model can be used to predict the occurrence date of other temperature-dependent phenological events in plants, such as bud break, leaf-unfolding, etc., assuming that the developmental rate curve of plants is similar to that of insects (Shi et al. 2017b). Considering that the growth and development of plants and insects commonly experience low- and mid-temperature zones, the linear model is widely used to express it (Trudgill and Perry 1994; Lonati et al. 2009). There is an intersection between the straight line of developmental rate and the temperature axis (i.e. $x$ axis) on the plane, which is referred to as developmental zero or lower developmental threshold (temperature) or base temperature (Trudgill and Perry 1994; Jarošík et al. 2002). The lower developmental threshold is a vital concept that is a theoretical critical starting point for development and below which the development terminates.

Temperature can also greatly affect the growth and organismic size of plants (Yin et al. 1995; Trudgill et al. 2000). Watts $(1971,1972 a, b, 1973,1974)$ studied the role of temperature in regulating the leaf extension in Zea mays Linn. and found that the relative rate of leaf extension was closely related to the soil temperature at a depth of $5 \mathrm{~cm}$ and shoot temperature at the meristematic region. The relationship between the relative rate of leaf extension and soil temperature (between 0 and $35^{\circ} \mathrm{C}$ ) was linear. Peacock $(1975 \mathrm{a}, \mathrm{b}, \mathrm{c})$ examined the effect of temperature on leaf growth for Lolium perenne Linn. and how leaf growth at different seasons was influenced by temperature in the stem apex. Angus et al. (1980, 1981, 1982) described the phasic development of different crops under different temperatures, and explored different models for fitting the response curve of development to daily mean temperature. Berone et al. (2007) analyzed the differences in the response of leaf elongation to moderately low temperatures between two grasses, Bromus stamineus E. Desv. and L. perenne. Jumrani et al. (2017) quantified the effect of high temperature on changes in leaf thickness, number of stomata on both adaxial and abaxial leaf surfaces, gas exchange, chlorophyll florescence parameters and seed yield in soybean.

The influence of temperature on seed germination rate has been studied in detail (e.g. Bierhuizen and Wagenvoort 1974; Covell et al. 1986; Ellis et al. 1986, 1987; Craufurd et al. 1996a, b, c; Jacobsen and Bach 2015). For instance, Craufurd et al. (1996a, b, c) examined the base, optimum and ceiling temperature of a range of cowpea genotypes (Vigna unguiculata (Linn.) Walp) from different habitats and latitudes for $50 \%$ seed germination and seedling emergence, and the thermal time at sub-optimal temperatures. They found that the estimated base temperature for $50 \%$ seed germination was higher for genotypes originating from habitats close to the equator than from semi-arid habitats. The estimated base temperatures for four genotypes were around $10{ }^{\circ} \mathrm{C}$. Trudgill et al. (2000) reviewed the thermal time basis for $50 \%$ seed germination in 20 British herbaceous plants, and summarized that the base temperature was in the range of $0-13{ }^{\circ} \mathrm{C}$, except $-1.8^{\circ} \mathrm{C}$ for Saxifraga tridactylites Linn. These estimates were all based on linear regression between $50 \%$ seed germination rate and temperature, and the coefficients of determination (i.e. $R^{2}$, a measurement for the goodness of fit of linear regression) ranged from 0.93 to 0.99 , which demonstrated the validity of linear model. Bois et al. (2006) also reported the linear relationship between four constant temperatures $\left(2,5,10,20^{\circ} \mathrm{C}\right)$ and $50 \%$ seed germination in 10 cultivars of quinoa (Chenopodium quinoa Willd.). The estimated lower developmental threshold for 10 cultivars ranged from -1 to $1{ }^{\circ} \mathrm{C}$, which is lower than those for insects, mites and spiders $\left(5-15^{\circ} \mathrm{C}\right)(\mathrm{Li}$ and Jackson 1996; Kiritani 2012). Jacobsen and Bach (2015) found that the relationship between temperature (constant temperatures in the range of $8-35{ }^{\circ} \mathrm{C}$ ) and germination rate of quinoa was linear only for the temperatures below the critical optimum level, and the base temperature for germination was $3{ }^{\circ} \mathrm{C}$. Rodriguez et al. (2016) conducted a more elaborate temperature-dependent developmental experiment on seed germination and seedling emergence of Cañahua (Chenopodium pallidicaule Aellen) by using a six temperature gradient $\left(3,5,10,14,20\right.$ and $\left.24^{\circ} \mathrm{C}\right)$, and they also considered the effect of sowing depth with a range of $0,5,10,25$ and $50 \mathrm{~mm}$ under three constant thermal environments $(5,15$ and $25^{\circ} \mathrm{C}$ ) on seedling emergence. There was also a strong linear 
relationship between temperature and $50 \%$ germination rate, and there were significant differences between seed germination percentage and burial depth. Shallow sowing depth (5, 10 and $25 \mathrm{~mm}$ ) resulted in higher germination percentages than the treatments of 0 and $50 \mathrm{~mm}$ burial depths. Overall, the linear model not only describes the temperature-dependent developmental rate of arthropods, but also describes the effect of temperature on the germination rate in plants.

In entomology the hypothesis of rate isomorphy states that for the same species, the lower developmental thresholds do not differ for different developmental stages (Jarošík et al. 2002, 2004; Shi et al. 2010; Kuang et al. 2012). Jarošík et al. (2002) studied the incidence of rate isomorphy by using seven species of mites and 342 species of insects. In the quasi-linear region of the relationship between developmental rate and temperature, the developmental stages for the same species have the same species-specific lower developmental threshold (Jarošík et al. 2004; Diaz et al. 2007). Kuang et al. (2012) generated comprehensive stage-specific developmental data (accurate hourly data) on Colaphellus bowringi Baly, and used five analytical methods to test the rate isomorphy hypothesis. They found no significant difference in the lower developmental thresholds among three developmental stages (including egg, larval and pupal stages). Sandhu et al. (2011) further demonstrated the validity of the rate isomorphy hypothesis using the bootstrap percentile based on the data of $C$. bowringi. The isomorphy hypothesis has not yet been tested in botany. However, it is important in phenological prediction for agriculture and forestry. The accumulated degree-days model is frequently used to predict the occurrence date of insect pest outbreaks and phonological stages in crops and plants, which is based on linear relationship between developmental rate and temperature (see Shi et al. 2017a for details). Base temperature (i.e. the lower developmental threshold), thermal constant and starting date are three important parameters of this method. Usually, the starting date can be estimated by the lowest correlation coefficient between the starting date candidate and the mean air temperatures from the starting date candidate and the predicted occurrence time of the phenological event. Thermal constant is the expected accumulative effective temperature above the base temperature from starting date to the occurrence date of the phenological event. Knowledge of the base temperature is needed before calculating the thermal constant. Some agricultural insect pests can be reared at different constant temperatures in growth chambers to estimate base temperature using linear regression. However, for tall plants especially for many tall trees, some developmental stages are impossible to be observed in growth chambers. Although it is theoretically feasible to carry out temperature-controlled experiments for small trees in greenhouses, the high cost makes it practically infeasible. The seeds and seedlings of plants are all smaller than the mature plants. According to the rate isomorphy hypothesis, the estimated base temperature for seed germination or seedling emergence can be used as a base temperature for other temperature-dependent phenological events, such as bud break and leaf emergence.

Bamboo, an important non-woody forestry resource and fast growing renewable plant, is one of the most important agricultural plants worldwide (Liese and Köhl 2015). Bambusoideae comprises of 116 genera and approximately 1439 species (Bamboo Phylogeny Group 2012), and are native to predominantly moist tropical and warm temperate climates around the world. In East and South Asia, bamboos are economically important landscape plants for fiber and food production. Successful germination is crucial in the life cycle of terrestrial angiosperms. Seeds that can effectively adapt to different environmental conditions and alter their germination behavior will be more likely to survive and achieve a high fitness. Bamboo seeds are no exception. In some bamboo species the vegetative state shows signs of persisting almost indefinitely. Woody bamboos have peculiar flowering characteristics with intervals ranging from several years to more than 100 years (Janzen 1976), so some bamboo seeds are very precious. Because bamboo reproduces by its rhizomes, it is difficult to conduct temperature-dependent developmental experiments with adult bamboos. However, if the base temperatures for different developmental stages of bamboo are the same (i.e. following the rate isomorphy hypothesis), it should be possible to use the same estimate of base temperature from an earlier stage that is readily calculable from a temperature-controlled experiment (e.g. seedling emergence or leaf-unfolding).

The main objectives of the present work were: (1) to examine the effects of five constant temperatures on the developmental times of seedling emergence and leafunfolding of two species of dwarf bamboos, Pleioblastus pygmaeus (Miq.) Nakai and Sasaella kongosanensis 'Aureostriatus' (Nakai) Nakai ex Koidz; (2) to test the rate isomorphy hypothesis across two different developmental stages in these bamboo species. These dwarf species have wide potential for use in landscaping (e.g., for "bamboo lawns") and leaf source exploitation for medicine and tea. Knowledge of seed germination and leaf expansion response to different temperatures could ensure accurate evaluation of suitable thermal ranges for these species, which can be helpful to predict geographically suitable planting areas in Mainland China.

\section{Materials and methods}

\section{Seed collection}

The seeds of P. pygmaeus and S. kongosanensis 'Aureostriatus' were collected from the Nanjing Forestry University campus $\left(118^{\circ} 48^{\prime} 17^{\prime \prime} \mathrm{E}, 32^{\circ} 4^{\prime} 44^{\prime \prime} \mathrm{N}\right)$ in May 2016. Figure 1 
illustrates the seed morphology of these two species. P. pygmaeus was brought to the university campus from Gulin Park, Nanjing, China in the 1980s, where it might have been brought from Japan during the Second World War. S. kongosanensis 'Aureostriatus' was brought from Fuji Bamboo Garden, Japan, in August 1984. The seeds used in this experiment were randomly selected from a larger pool of seeds collected from the Nanjing Forestry University campus.

\section{Temperature-dependent experiment}

Five chambers with measure accuracy of $\pm 0.5{ }^{\circ} \mathrm{C}$ (GTOP380B, 380L, $66 \times 66 \times 177 \mathrm{~cm}$, Zhejiang Top Instrument Co., Ltd., Hangzhou City, Zhejiang Province, P. R. China) were used to simulate five constant thermal environments from 18.5 to $28.5^{\circ} \mathrm{C}$ with an increment of $2.5^{\circ} \mathrm{C}$ and photoperiod 13:11 LD. Under each temperature, 500 seeds were assigned to six plastic boxes. Boxes were $28 \times 19 \times 10 \mathrm{~cm}$ (length $\times$ width $\times$ height) inside, and were filled with soil to a depth of $6.5-7.5 \mathrm{~cm}$ in depth soil (Fig. S1). The soil was a mixture of $48 \%$ turf, $48 \%$ yellow brown soil, and $4 \%$ perlite. Seeds ( $83-85$ per box) were sown $0.3 \mathrm{~cm}$ under the surface

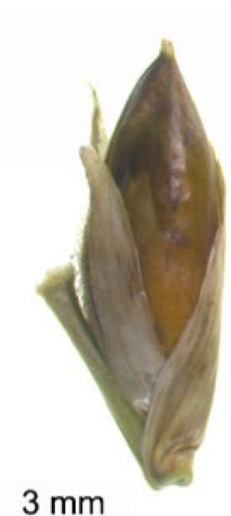

$$
3 \mathrm{~mm}
$$
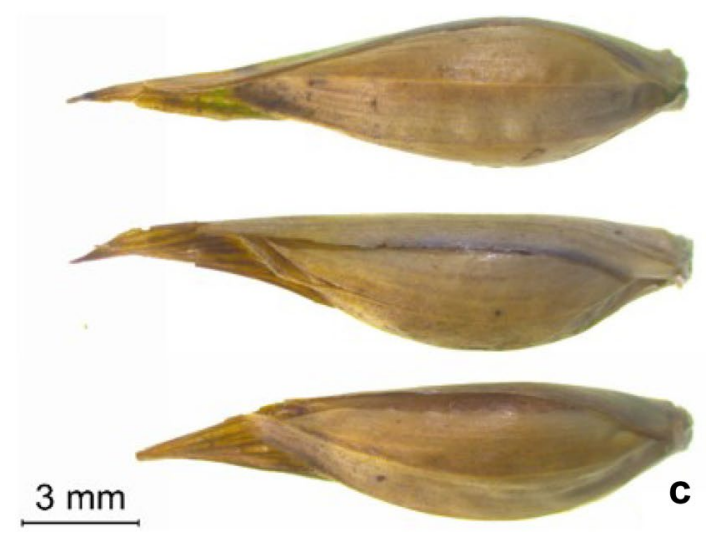

Fig. 1 Morphological comparison in seeds between P. pygmaeus (a, b) and S. kongosanensis 'Aureostriatus' (c, d). a Shows the seeds of P. pygmaeus with the palea and lemma; b shows the seeds of P. pyg- soil on 22 May 2016 for P. pygmaeus, and 28 May 2016 for S. kongosanensis 'Aureostriatus'. During the experiment, the relative humidity was controlled within the range from 80 to $90 \%$.

After sowing, the development was observed twice per day: 9:00 a.m. and 21:00 p.m. The time of seedling emergence is defined as the time from the sowing to when the seedling first emerged from the soil. The time from leafunfolding of the first leaf to the third leaf was recorded. The time from seedling emergence to the unfolding of the first leaf or the second leaf was too short to reduce the standard error within a reasonable range (see Table 1 for detail). Below, only the time from sowing to seedling emergence (stage I), and the time from seedling emergence to unfolding of the third leaf (stage II) were analyzed. All experimental data can be found in Electronic Supplementary Material.

\section{Data analysis}

Analysis of variance (ANOVA) was performed to compare the differences of seed lengths and seed weights. Tukey HSD test was used to check whether there was significant difference in a

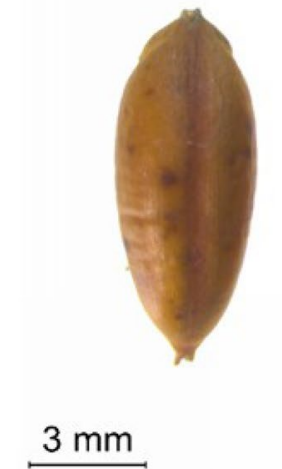

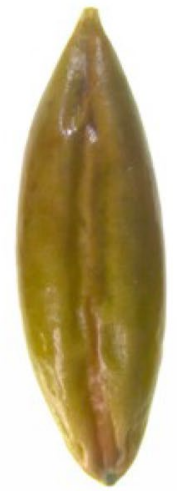

$3 \mathrm{~mm}$
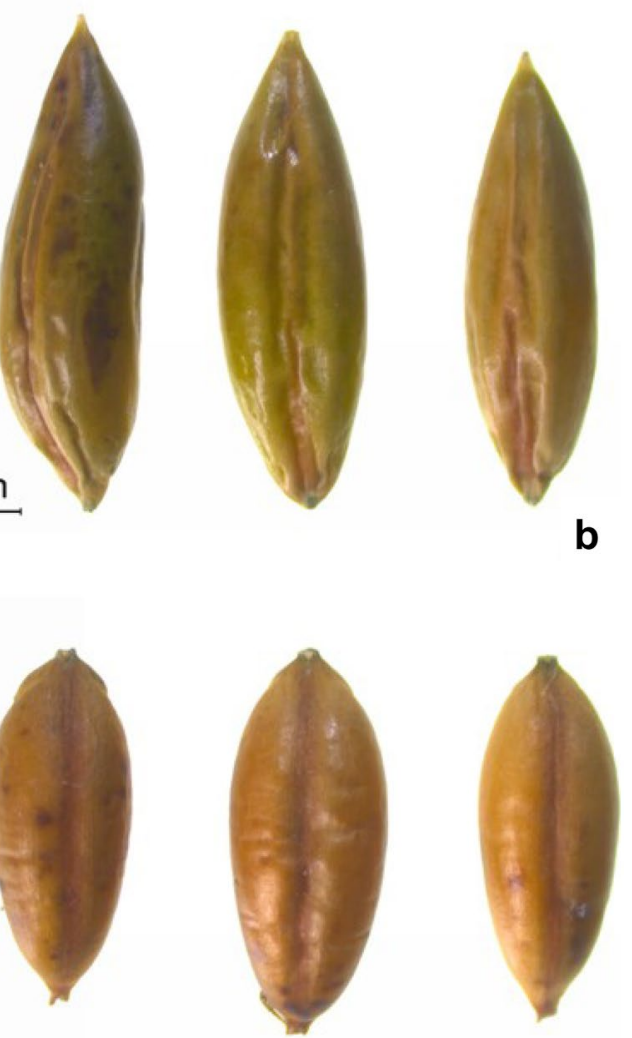

d maeus without the palea and lemma; c shows the seeds of S. kongosanensis 'Aureostriatus' with the palea and lemma; d shows the seeds of S. kongosanensis 'Aureostriatus' without the palea and lemma 
Table 1 Effects of temperature on the seedling emergence and leaf-unfolding of P. pygmaeus

\begin{tabular}{llllll}
\hline Stage (days) & \multicolumn{1}{l}{ Temperature } & & & \\
\cline { 2 - 5 } & $18.5{ }^{\circ} \mathrm{C}$ & $21{ }^{\circ} \mathrm{C}$ & $23.5{ }^{\circ} \mathrm{C}$ & $26{ }^{\circ} \mathrm{C}$ & $28.5{ }^{\circ} \mathrm{C}$ \\
\hline Seedling emergence & $17 \pm 4.4(264)$ & $14.2 \pm 3.86(268)$ & $12.29 \pm 3.88(282)$ & $10.53 \pm 3.06(300)$ & $9.54 \pm 2.91(297)$ \\
& $8.42-34.92$ & $5.88-31.38$ & $6.38-29.9$ & $5.88-23.38$ & $5.88-24.88$ \\
First leaf-unfolding & $7.87 \pm 3.6(239)$ & $6.61 \pm 2.67(238)$ & $4.72 \pm 2.6(253)$ & $3.77 \pm 1.84(276)$ & $3.5 \pm 1.66(270)$ \\
& $0.94-22.97$ & $0.44-15.99$ & $0.5-18.99$ & $0.48-10.99$ & $0.5-11.97$ \\
Second leaf-unfolding & $7.44 \pm 3.61(228)$ & $6.4 \pm 4.28(227)$ & $4.75 \pm 2.01(246)$ & $4.73 \pm 3.85(259)$ & $4.27 \pm 2.78(263)$ \\
& $0.48-26$ & $0.48-41.97$ & $0.47-18.47$ & $0.48-45.51$ & $0.5-28$ \\
Third leaf-unfolding & $8.97 \pm 3.33(203)$ & $7.49 \pm 2.78(210)$ & $6.18 \pm 3.31(231)$ & $5.99 \pm 5.21(244)$ & $5.23 \pm 4.86(252)$ \\
& $1.52-27.53$ & $0.53-18.52$ & $0.52-28.46$ & $1.95-44.01$ & $0.52-44.53$ \\
$1+2+3$ leaf-unfolding & $23.37 \pm 6.06(203)$ & $19.83 \pm 4.7(210)$ & $15.22 \pm 4.34(230)$ & $13.97 \pm 6.22(243)$ & $12.75 \pm 6.23(247)$ \\
& $9.47-52.99$ & $9-39.47$ & $6.47-40.47$ & $5.99-53.5$ & $5.48-53$ \\
\hline
\end{tabular}

Here, ' $1+2+3$ ' denotes the total progress from the seeding emergence to the unfolding of the third leaf. Mean \pm SD (with sample size) and the minimum to maximum values of developmental time are listed in every cell

developmental time between different temperatures, and also whether there was significant difference in the developmental time between the two species under the same temperature. The survival rates of stages I and II were also calculated. Developmental rate is the reciprocal of developmental time, and it is linearly associated with temperature in the mid-temperature range (Campbell et al. 1974):

$r=a+b T$,

where $r$ is the developmental rate at temperature $T ; a$ and $b$ are constants. Two important thermal constants are closely related to this linear equation: the lower developmental threshold $(t)$ and the sum of effective temperature $(k)$. Their definitions are as follows:

$t=-\frac{a}{b}$,

$k=\frac{1}{b}$

The lower developmental threshold represents a 'conceptual' temperature threshold below which development terminates, and the sum of effective temperatures represents the heat accumulation required for completing a specified developmental stage. For estimating the parameters of Eq. (1), previous studies usually use the method of ordinary least squares under the assumption of homoscedasticity (Campbell et al. 1974). However, the variance of developmental rates under different temperatures is usually heterogeneous (Ratkowsky 1990; Ratkowsky and Reddy 2017; Shi et al. 2017c). Therefore, the relationship between the mean $(m)$ and variance $(v)$ of developmental rates of plants and poikilotherms should follow a power law (Taylor 1961; Eisler et al. 2008; Cohen and Xu 2015; Shi et al. 2017c):

$v=\alpha m^{\beta}$, where $\alpha$ and $\beta$ are constants. The exponent of Taylor's power law has long been debated, and its estimate usually ranges from 1 to 3 (Eisler et al. 2008). If Taylor's power law held for the developmental rate, it would suggest that the method of ordinary least squares might lead to inaccurate parameter estimates. In this case, the method of weighted least squares can work better for parameter estimation, which usually uses the reciprocals of variances as the weights. In the present analysis, we first checked whether the relationship between the mean and variance of developmental rates under different temperatures followed Taylor's power law. If so, we then used the method of weighted least squares to perform a linear regression for Eq. (1); otherwise, the method of ordinary least squares was used.

The difference of lower developmental thresholds between stage I and stage II for each bamboo species was tested using the bootstrap percentile method (Efron and Tibshirani 1993; Sandhu et al. 2011; Efron and Hastie 2016). The bootstrap percentile method tests the difference of two parameters by observing whether the $95 \%$ confidence interval (CI) of the difference between the bootstrap replicates of one parameter and those of the other parameter includes zero. If the confidence interval includes zero, there is no significant difference.

If the method of weighted least squares is used to estimate the parameters of Eq. (1), the formulae of standard errors for the two thermal constants proposed by Campbell et al. (1974) will not apply. If so, we used the bootstrap method to calculate the standard errors for the estimates of $t$ and $k$.

The survival rates $(S)$ of stages I and II were also calculated. The square root of survival rate was transformed using the arcsine function. We then checked whether there was significant difference in the survival rate between the two bamboo species under different temperatures:

$\arcsin (\sqrt{S})=\beta_{0}+\beta_{1} q+\beta_{2} T$, 
where $q$ is a categorical variable of bamboo species $(=1$ or 2); $T$ represents temperature; and the other parameters are constants. When the variable $q$ is dropped in Eq. (5), we can determine the significance of temperature effect on survival rates at five constant temperatures by checking the statistical significance of the regression coefficient of slope. All analyses were conducted using the software R (version 3.2.2; R Core Team 2015). Package 'agricolae' was used to carry out the Tukey HSD test.

\section{Results}

\section{Comparison of seed sizes}

The seed length difference between P. pygmaeus and S. kongosanensis 'Aureostriatus' was significant $\left(F_{1,998}=1241\right.$, $p<0.01)$, but the difference in seed dry weights was not significant $\left(F_{1,998}=1.513, p=0.219>0.05\right)$ (Fig. 2).

\section{Effect of temperature on development}

Tables 1 and 2 provide the developmental time under five constant temperatures for two bamboo species. Figure 3 shows the comparison of developmental time of two bamboo species under different temperatures. The Tukey HSD test demonstrated that the developmental time declined significantly with increase in temperature for both bamboo species.

The mean and variance of developmental rates followed Taylor's power law for both developmental stages (Fig. 4). Consequently, we used the method of weighted least squares to perform linear regression between temperature and developmental rate (Fig. 5). Based on the estimates of the linear model parameters, the lower developmental thresholds and sums of effective temperatures with their $95 \%$ confidence intervals were estimated (Table 3). The estimates of lower developmental thresholds for stages I and II of $P$. pygmaeus are 6.17 and $8.67{ }^{\circ} \mathrm{C}$, respectively; and the estimates of lower developmental thresholds for stages I and II of S. kongosanensis 'Aureostriatus' are 12.36 and $8.13{ }^{\circ} \mathrm{C}$, respectively. The 95\% confidence interval of the differences in lower developmental thresholds for the two stages of $P$. pygmaeus does not include zero, indicating a significant difference (Fig. 5c); and so does the confidence interval for $S$. kongosanensis 'Aureostriatus' (Fig. 5f). Thus, the lower developmental thresholds at different stages differed for both species.

For the two developmental stages (i.e. seedling emergence and unfolding of the third leaf), the survival rates were significantly affected by temperature $(p<0.05$; Fig. 6). For the first stage, the survival rates of $P$. pygmaeus were significantly higher than those of S. kongosanensis 'Aureostriatus' $(p=0.00175<0.05)$. For the second stage, the survival rates of the two bamboo species
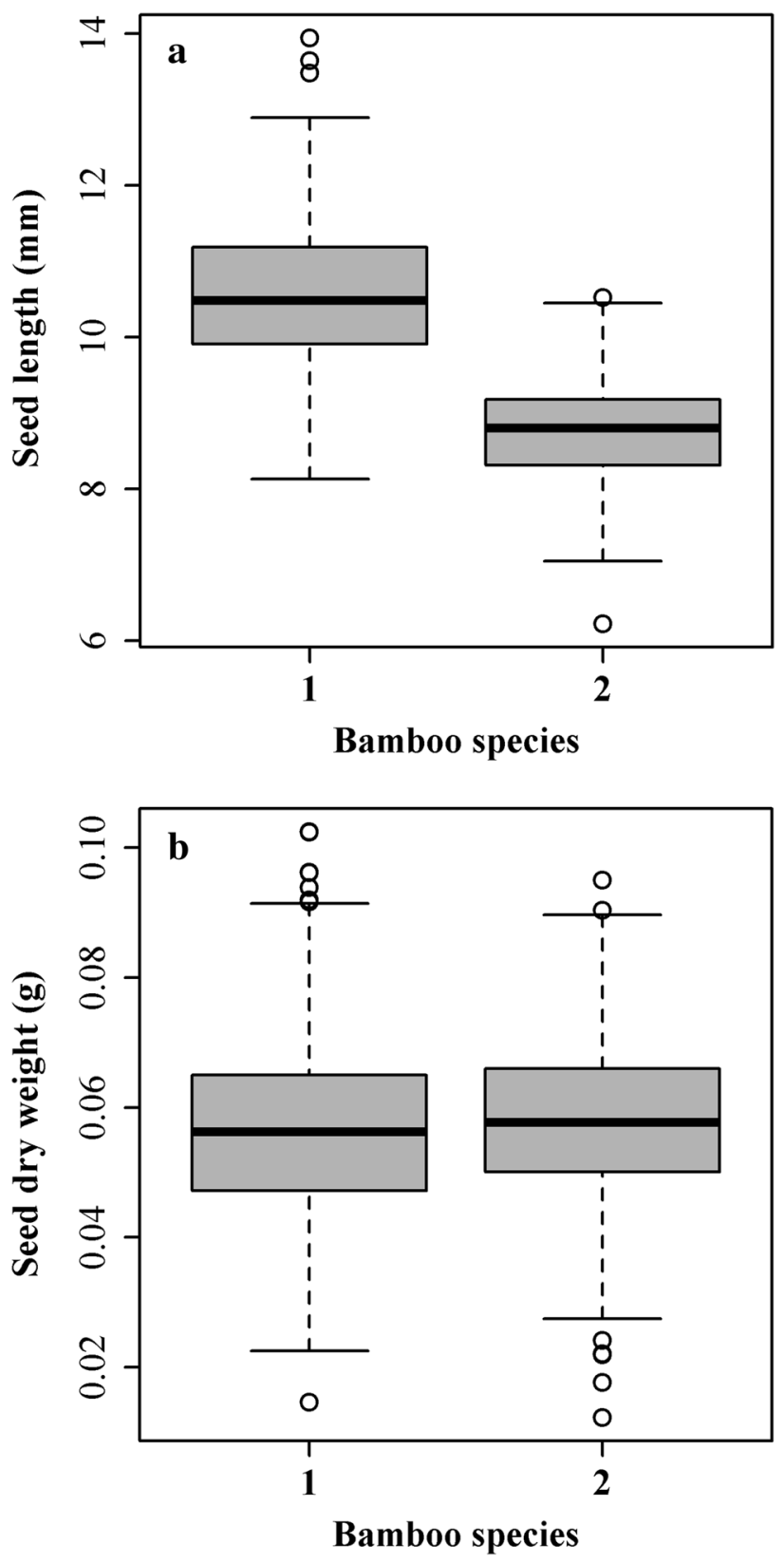

Fig. 2 Comparison of $\mathbf{a}$ seed lengths and $\mathbf{b}$ seed dry weights between two species of dwarf bamboo using boxplots. ' 1 ' denotes $P$. pygmaeus, and '2' denotes $S$. kongosanensis 'Aureostriatus'. The width of box represents the difference of the upper and lower quartiles. The length of upper whisker equals 1.5 times the width of box when the distance from the largest extreme value to upper quartile is larger than 1.5 times the width of box; otherwise, it equals the largest extreme value. The length of lower whisker is similar to that of upper whisker, but it is related to the lowest extreme value. In 500 samples, the existence of a small number of extreme values (small open circles) of seed dry weight and length is normal

under the same temperature showed no significant difference $(p=0.4114>0.05)$. Temperature showed a significant influence on the survival rates of the two stages in both species except in the leaf-unfolding stage of $S$. 
Table 2 Effects of temperature on the seedling emergence and leaf-unfolding of S. kongosanensis 'Aureostriatus'

\begin{tabular}{llllll}
\hline Stage (days) & \multicolumn{1}{l}{ Temperature } & & & \\
\cline { 2 - 5 } & $18.5{ }^{\circ} \mathrm{C}$ & $21{ }^{\circ} \mathrm{C}$ & $23.5{ }^{\circ} \mathrm{C}$ & $26{ }^{\circ} \mathrm{C}$ & $28.5{ }^{\circ} \mathrm{C}$ \\
\hline Seedling emergence & $54.52 \pm 19.8(144)$ & $41.89 \pm 17.04(205)$ & $33.18 \pm 16.18(242)$ & $30.02 \pm 17.8(244)$ & $23.2 \pm 13.57(252)$ \\
& $15.88-93.38$ & $15.9-84.88$ & $10.9-75.38$ & $7.39-75.9$ & $6.9-66.4$ \\
First leaf-unfolding & $13.18 \pm 7.22(137)$ & $10.1 \pm 5.14(192)$ & $8.6 \pm 6.51(233)$ & $7.05 \pm 3.99(234)$ & $6.15 \pm 3.12(240)$ \\
& $0.49-44.01$ & $0.97-33.5$ & $0.48-50.49$ & $1-32.51$ & $0.96-22.52$ \\
Second leaf-unfolding & $13.81 \pm 5.89(130)$ & $10.68 \pm 4.07(184)$ & $8.93 \pm 3.94(221)$ & $8.28 \pm 5.44(222)$ & $7.22 \pm 4.41(223)$ \\
& $0.49-50.47$ & $0.52-31.99$ & $0.47-37$ & $0.52-49.99$ & $0.5-27$ \\
Third leaf-unfolding & $14.09 \pm 4.57(115)$ & $12.56 \pm 3.81(164)$ & $10.9 \pm 4.39(203)$ & $9.41 \pm 3.8(198)$ & $7.96 \pm 3.86(206)$ \\
& $0.5-32.97$ & $1.49-27.48$ & $0.01-25.99$ & $1.98-27.47$ & $0.49-28$ \\
$1+2+3$ leaf-unfolding & $39.81 \pm 10.12(115)$ & $32.44 \pm 7.42(164)$ & $27.31 \pm 7.78(202)$ & $23.64 \pm 6.65(198)$ & $21.09 \pm 7.45(204)$ \\
& $21.51-88.49$ & $11.99-56.97$ & $12.01-54.53$ & $12-52.01$ & $8.98-51.51$ \\
\hline
\end{tabular}

Here, ' $1+2+3$ ' denotes the total progress from the seeding emergence to the unfolding of the third leaf. Mean \pm SD (with sample size) and the minimum to maximum values of developmental time are listed in every cell

Fig. 3 Comparison of temperature-dependent developmental times: $a$ at the seedling emergence stage between two bamboo species, and $\mathbf{b}$ from seedling emergence to third leaf-unfolding stage. P. pygmaeus is represented by open white bar, and S. kongosanensis 'Aureostriatus' is represented by closed gray bar
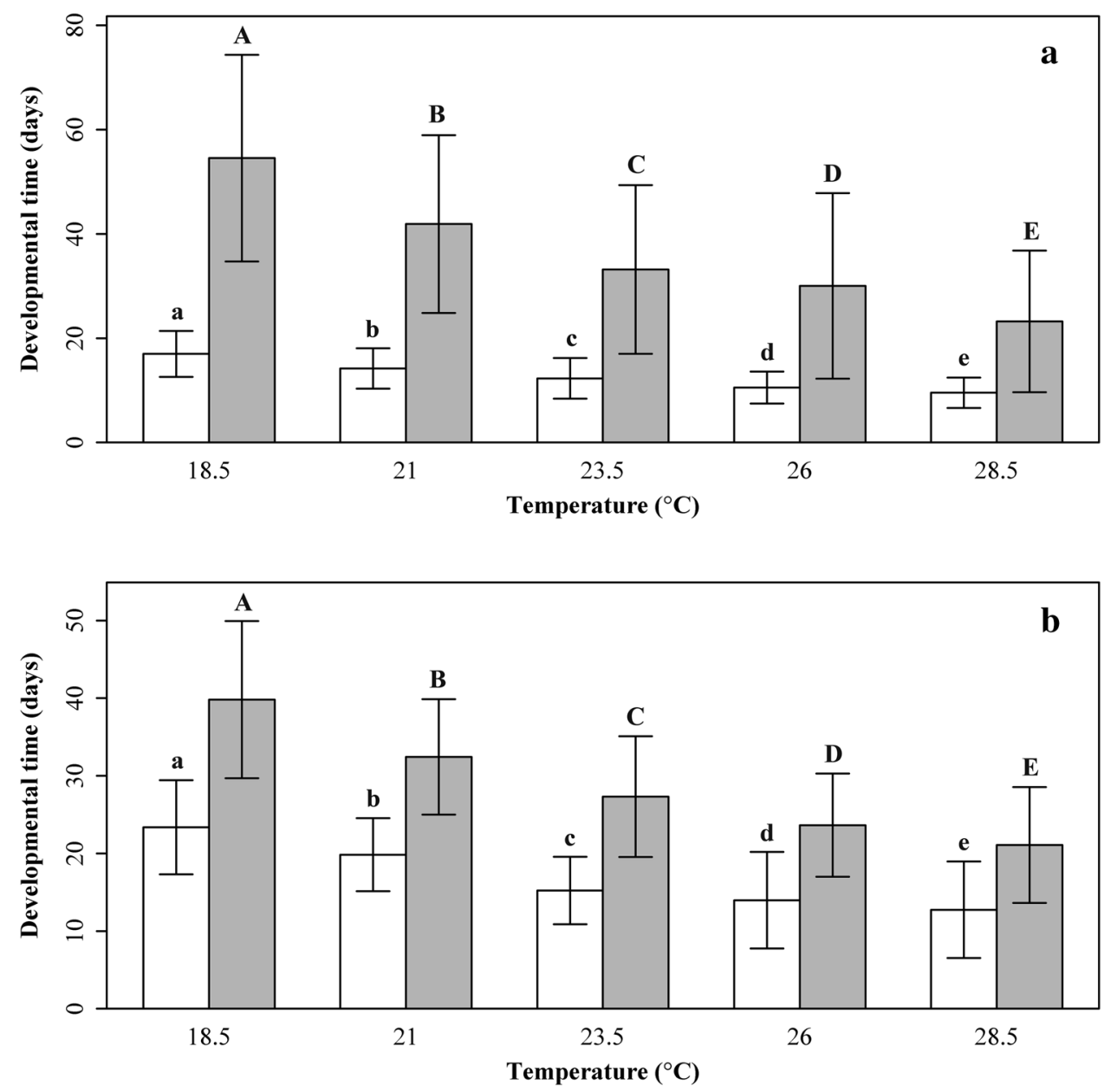

kongosanensis 'Aureostriatus'. The corresponding $p$ values for four slopes were 0.0143 (at stage I for the first species), 0.0136 (at stage II for the first species), 0.04 (stage I for the second species), and 0.559 (at stage II for the second species), respectively.

\section{Discussion}

In the mid-temperature zone, the linear relationship between developmental rate of poikilotherms and temperature is well documented in the literature (Uvarov 1931; 
Fig. 4 Taylor's power law between the mean and variance of developmental rates of the seedling emergence and leafunfolding for both bamboo species. The linear equation is used to fit the log-transformed data of mean and variance of developmental rate. The goodness of fit is evaluated by the coefficient of determination $\left(R^{2}\right)$. The estimate of slope and the corresponding $95 \%$ confidence interval are also provided
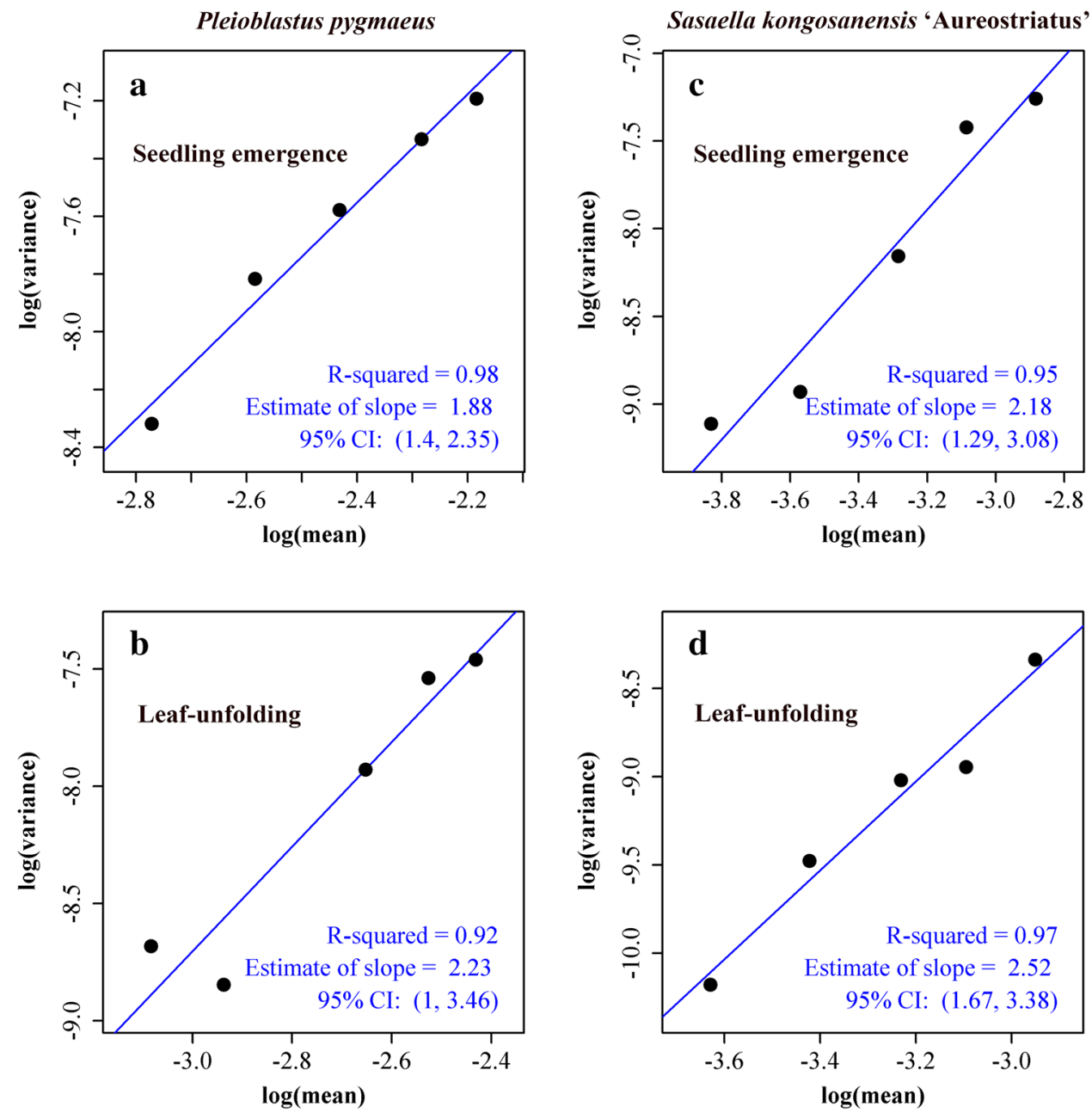

Sharpe and DeMichele 1977). The straight line between developmental rate and temperature in this zone is usually regarded as an approximation of the reaction rate curve of thermodynamics (Sharpe and DeMichele 1977). In the whole thermal range of development, many non-linear models are used for describing the effect of temperature on developmental rate of plants and poikilotherms (Shi and Ge 2010; Shi et al. 2016a, 2017d; Mirhosseini et al. 2017; Quinn 2017a; Ratkowsky and Reddy 2017; and references therein). Based on reaction kinetics, two nonlinear models [the Sharpe-Schoolfield-Ikemoto (SSI) model and the Ratkowsky-Olley-Ross (ROR) model] showed many advantages over the pure statistical descriptive models (Sharpe and DeMichele 1977; Schoolfield et al. 1981; Ikemoto 2005, 2008; Ratkowsky et al. 2005; Ikemoto et al. 2013; Shi et al. 2011, 2017d). The parameters of these two models have detailed thermodynamic meanings that can predict the probabilities of the rate-controlling enzyme being in the active state at different temperatures (Sharpe and DeMichele 1977; Ratkowsky et al. 2005). The maximum probability of this enzyme can be used in predicting an intrinsic optimum temperature for development (Ikemoto et al. 2013; Shi et al. 2017d). Ikemoto (2005, 2008) compared the SSI model curve in the mid-temperature range and the fitted straight line based on the reduced major axis method, and found that the former could be approximated from the latter. Shi et al. $(2011,2012)$ and Ikemoto et al. (2013) calculated the tangent of the SSI model at the intrinsic optimum temperature, and found that it approximately overlaps with the fitted straight line using the temperature-dependent developmental rates in the midtemperature range. Thus the linear relationship between developmental rate and temperature in this range is likely to be an approximation of the tangent of the nonlinear response curve at the intrinsic optimum temperature.

Usually, the intrinsic optimum temperature lies in the vicinity of the abscissa of midpoint in the developmental rate straight line between base temperature and the maximal developmental rate temperature (Shi et al. 2011, 2012; Ikemoto et al. 2013; Yamamoto et al. 2017). The intrinsic optimum temperature is thus lower than the temperature associated with the maximal developmental rate. Martin 
Fig. 5 Linear fit to the temperature-dependent developmental rates of the seedling emergence (a, d) and leaf-unfolding (b, e) for both bamboo species. c, $\mathbf{f}$ Exhibit the density distribution of the difference in lower developmental threshold between the bootstrap replicates of seedling emergence stage and those of leaf-unfolding stage (from the seedling emergence to the unfolding of the third leaf)
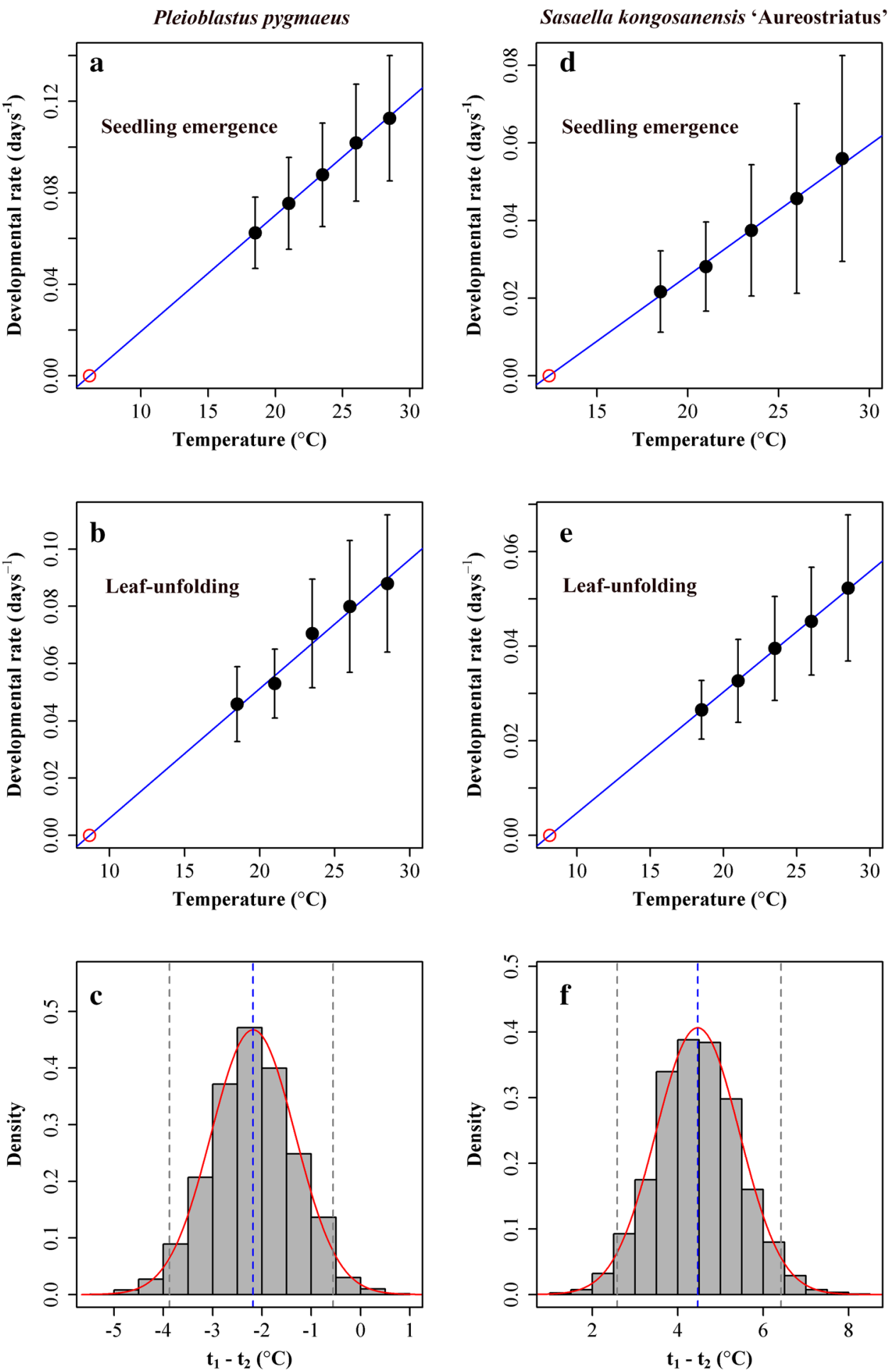

and Huey (2008) suggested that the 'optimal' temperature is only slightly lower than the temperature for maximal development or growth, contrasting to the predictions from the SSI and ROR models which suggest a larger difference between the two temperatures. If the above conclusion can be extended to plants, the intrinsic optimum temperatures for the stages of seedling emergence and unfolding of the third leaf can be estimated. However, considering the data of developmental rate at high temperatures are lacking in the current experiment, we have not used the SSI model to calculate the intrinsic optimum temperatures at the two stages. The five constant temperatures used in the current experiment exactly lie in the mid-temperature region of the developmental stages of interest. In view of the highest 
Table 3 Estimates of lower development threshold $(t)$ and sum of effective temperatures (k)

\begin{tabular}{|c|c|c|c|c|}
\hline \multirow[t]{2}{*}{ Parameter } & \multicolumn{2}{|l|}{ P. pygmaeus } & \multicolumn{2}{|c|}{ S. kongosanensis 'Aureostriatus' } \\
\hline & Estimate $\pm \mathrm{SD}$ & $95 \%$ confidence interval & Estimate $\pm \mathrm{SD}$ & $95 \%$ confidence interval \\
\hline$t_{1}$ & $6.17 \pm 0.61$ & $(4.83,7.23)$ & $12.36 \pm 0.61$ & $(11.38,13.76)$ \\
\hline$k_{1}$ & $196.75 \pm 7.20$ & $(184.34,212.31)$ & $296.32 \pm 17.87$ & $(254.60,325.37)$ \\
\hline$t_{2}$ & $8.67 \pm 0.61$ & $(7.05,9.40)$ & $8.13 \pm 0.80$ & $(6.54,9.64)$ \\
\hline$k_{2}$ & $221.38 \pm 9.64$ & $(207.88,245.99)$ & $391.71 \pm 21.26$ & $(351.44,434.20)$ \\
\hline
\end{tabular}

Subscript ' 1 ' represents the stage of seedling emergence, and subscript ' 2 ' represents the stage from the seedling emergence to the unfolding of the third leaf
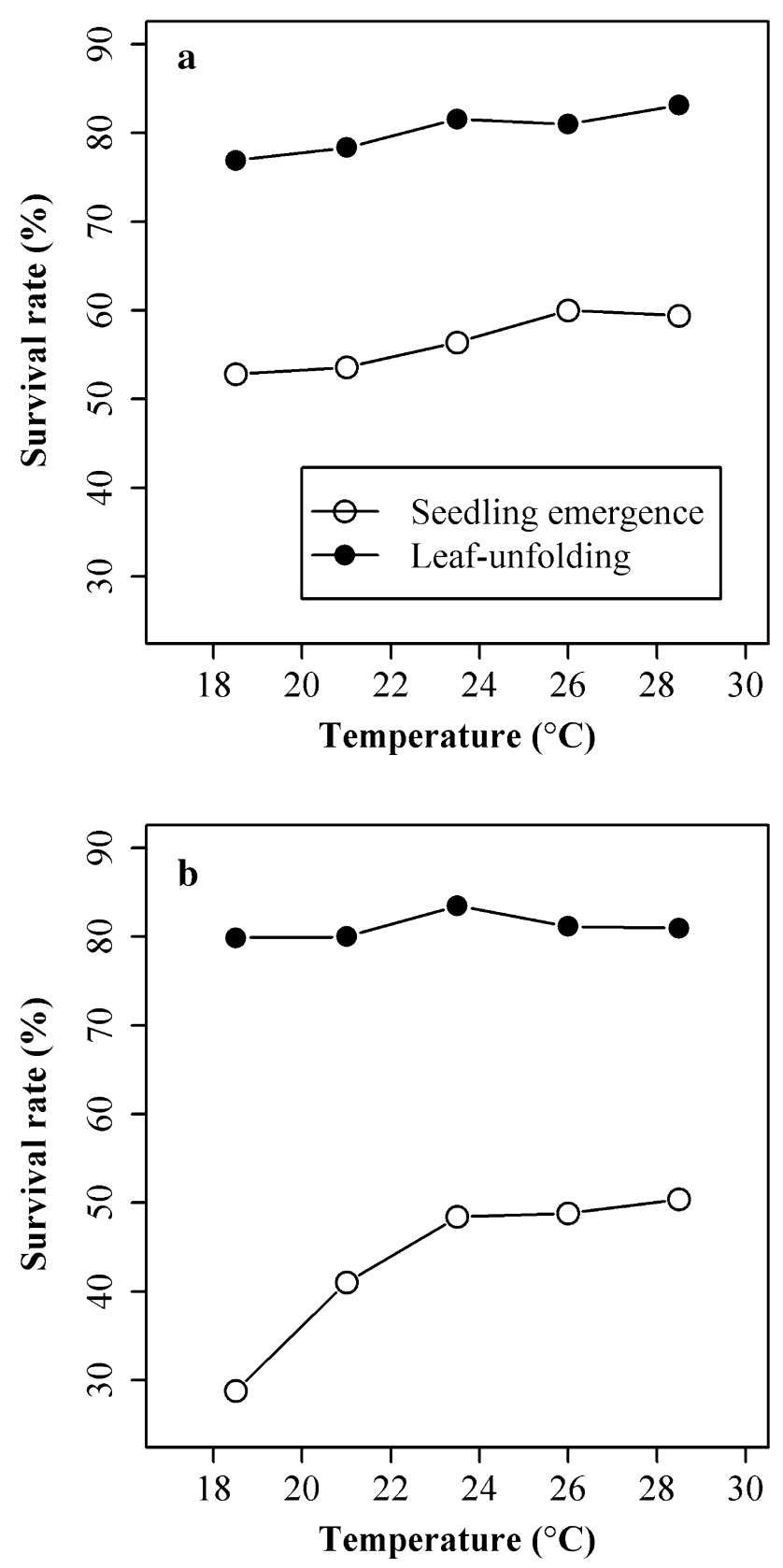

Fig. 6 Comparison of survival rates of two bamboo species at two stages: a denotes $P$. pygmaeus, and $\mathbf{b}$ denotes $S$. kongosanensis 'Aureostriatus' survival rates shown in Fig. $6,23.5^{\circ} \mathrm{C}$ appears to be closer to the theoretical value of the intrinsic optimum temperature for these two developmental stages. Shi et al. (2013) showed that the intrinsic optimum temperature for terrestrial ectotherms might be around $20{ }^{\circ} \mathrm{C}$ (ranged from 15 to $25^{\circ} \mathrm{C}$ ). Ikemoto (2003) demonstrated that there is a common intersection among the developmental rate straight lines of a group of closely related arthropods within the same taxon, describing their same developmental rates. Ikemoto (2005) further hypothesized that the abscissa of this common intersection is the intrinsic optimum temperature for development. This common intersection hypothesis was further confirmed by Bonato et al. (2011) using two families of arthropods. The present results do not support the common intersection hypothesis, because the developmental rate straight lines at the seedling emergence stage between two bamboo species from the same subfamily (Bambusoideae) do not intersect (Fig. 5a, d).

Although the rate isomorphy hypothesis was demonstrated to hold for many arthropods (Jarošík et al. 2002, 2004; Shi et al. 2010; Kuang et al. 2012), it does not hold for the bamboos investigated in this study. A possible reason is pseudo-replication at each temperature (Oksanen 2001), because any difference between the actual temperature and the programmed temperature of a growth chamber would cause all replicates to deviate from the theoretical distribution. Having more chambers, however, is difficult in practice because of very high cost and space limitations. To our knowledge, all reported temperature-dependent development of arthropods and plants used only one growth chamber at each temperature. In our results (Fig. 5), the mean developmental rates of seedling emergence at different temperatures in each species were almost in a straight line (Fig. 5a, d), suggesting pseudo-replication was not a problem. Similarly, the mean development rates of unfolding of the third leaf were also in a straight line except slight deviations in $P$. pygmaeus at 21 and $23.5^{\circ} \mathrm{C}$. The method of weighted least squares was used to assess the influence of deviations on linear fitting (Shi et al. 2017c). Overall, the estimates for lower developmental thresholds for each stage in both species are reliable and our test of the rate isomorphy hypothesis is supported. Surprisingly, we did not find a similar order of lower 
developmental thresholds for the two growth stages in either species. The lower developmental threshold for stage I was lower than stage II in P. pygmaeus $\left(6.17\right.$ versus $8.67{ }^{\circ} \mathrm{C}$ ), while stage I had a higher threshold than stage II in S. kongosanensis 'Aureostriatus' (12.36 versus $\left.8.13^{\circ} \mathrm{C}\right)$. This result necessitates further investigation of other plants.

Taylor's power law [TPL; see Eq. (4)] is an important ecological finding that was first proposed to explain the power-law relationship between the mean and variance of insect numbers in different quadrats (Taylor 1961), and then many studies found that the mean and variance of population dynamics of animals and plants at different investigation times also followed this law (e.g. Kilpatrick and Ives 2003; Giometto et al. 2015). The exponent ' $\beta$ ' of TPL normally ranges from 1 to 3 (Eisler et al. 2008), but in most cases it lies between 1 and 2 (Xiao et al. 2015 and references therein). There is debate on whether the exponent of TPL is biologically meaningful and what has led to the range from 1 to 2 (Cohen and Xu 2015; Xiao et al. 2015; Shi et al. 2016b). It is obvious that TPL is a special case of the powerlaw relationship between two variables (Newman 2005), and it has also been found in abiotic situations (Eisler et al. 2008). Shi et al. (2017c) found that TPL holds for the relationship between mean and variance of developmental rates of $C$. bowringi at different constant temperatures. For three developmental stages, the estimates of TPL's exponents were approximately '2' (see Fig. 3 published in Shi et al. 2017c). Similarly, the present study shows that all the $95 \%$ confidence intervals of four estimates of TPL's exponents included ' 2 '. The intervals are too wide because of limited number of data points (only five temperatures), and the accuracy for the exponent's estimate is not ideal. However, TPL is at least demonstrated to hold for the mean and variance of developmental rates of two bamboo species (all $p$ values of slope $<0.05$ and $R^{2} \geq 0.92$ ). We believe that TPL between mean and variance of developmental rates also holds for other arthropods and plants. However, to confirm if the estimate is equal to 2 or not, further studies are required. If the exponent is equal to 2 , we will have a conclusion that the coefficient of variation $(\mathrm{CV}=\sqrt{\text { variance }} /$ mean $\times 100 \%)$ of developmental rates at different temperatures is constant.

We observed a linear relationship between developmental rates and the ambient temperature at the stages of seedling emergency and leaf-unfolding for two dwarf bamboos. For each bamboo species, the lower thermal thresholds of two developmental stages differed significantly, refuting the rate isomorphy hypothesis initially proposed for arthropods. The TPL holds for the mean-variance relationship of developmental rates at different temperatures, but the exponents are in the vicinity of 2 , indicating a constant coefficient of variation in developmental rates.
Author contribution statement SL and PS designed the experiment; LS, TF, LZ, FL and YD carries out this experiment; PS analyzed the data; SL, PS, CH and HSS wrote the manuscript. All authors read and commented on this manuscript.

Acknowledgements We are thankful to the Communicating Editor and two anonymous reviewers for their comments on this paper. This work was financially supported by the National Key Research \& Development Program of China (2016YFD0600901); Jiangsu Province Support Project (LYSX[2016]04; BE2016304); the National Natural Science Foundation for Young Scholars of China (31400348 and 31000294) and the Priority Academic Program Development of Jiangsu Higher Education Institutions.

\section{Compliance with ethical standards}

Conflict of interest The authors declare that they have no conflict of interest.

\section{References}

Angus JF, Cunningham RB, Moncur MW, Mackenzie DH (1980) Phasic development in field crops. I. Thermal response in the seedling phase. Field Crop Res 3:365-378. https://doi.org/10.1016/03784290(80)90042-8

Angus JF, Mackenzie DH, Morton R, Schafer CA (1981) Phasic development in field crops II. Thermal and photoperiodic responses of spring wheat. Field Crop Res 4:269-283. https:// doi.org/10.1016/0378-4290(81)90078-2

Angus JF, Mackenzie DH, Myers RJK, Foale MA (1982) Phasic development in field crops. III. The pseudocereals, buckwheat and grain amaranth. Field Crop Res 5:305-318. https://doi. org/10.1016/0378-4290(82)90033-8

Bamboo Phylogeny Group (2012) An updated tribal and subtribal classification of the bamboos (Poaceae: Bambusoideae). Bamboo Sci Cult J Am Bamboo Soc 24:1-10

Berone G, Lattanzi F, Colabelli M, Agnusdei M (2007) A comparative analysis of the temperature response of leaf elongation in Bromus stamineus and Lolium perenne plants in the field: intrinsic and size-mediated effects. Ann Bot 100:813-820. https://doi. org/10.1093/aob/mcm174

Bierhuizen JF, Wagenvoort WA (1974) Some aspects of seed germination in vegetables. 1 . The determination and application of heat sums and minimum temperature for germination. Sci Hortic 2:213-219. https://doi.org/10.1016/0304-4238(74)90029-6

Bois JF, Winkel T, Lhomme JP, Raffaillac JP, Rocheteau A (2006) Response of some Andean cultivars of quinoa (Chenopodium quinoa Willd.) to temperature: effects on germination, phenology, growth and freezing. Eur J Agron 25:299-308. https://doi. org/10.1016/j.eja.2006.06.007 (Get rights and content)

Bonato O, Ikemoto T, Shi P, Ge F, Sun Y, Cao H (2011) Commonintersection hypothesis of development rate lines of ectotherms within a taxon revisited. J Therm Biol 36:422-429. https://doi. org/10.1016/j.jtherbio.2011.07.009

Campbell A, Frazer BD, Gilbert N, Gutierrez AP, Mackauer M (1974) Temperature requirements of some aphids and their parasites. J Appl Ecol 11:431-438. https://doi.org/10.2307/2402197

Cohen JE, Xu M (2015) Random sampling of skewed distributions implies Taylor's power law of fluctuation scaling. Proc 
Natl Acad Sci USA 112:7749-7754. https://doi.org/10.1073/ pnas. 1503824112

Covell S, Ellis RH, Roberts EH, Summerfield RJ (1986) The influence of temperature on seed germination rate in grain legumes I. A comparison of chickpea, lentil, soyabean and cowpea at constant temperatures. J Exp Bot 37:705-715. https://doi. org/10.1093/jxb/37.5.705

Craufurd PQ, Ellis RH, Summerfield RJ, Menin L (1996a) Development in cowpea (Vigna unguiculata). I. The influence of temperature on seed germination and seedling emergence. Exp Agric 32:1-12

Craufurd PQ, Qi A, Ellis RH, Summerfield RJ, Roberts EH (1996b) Development in cowpea (Vigna unguiculata). II. Effect of temperature and saturation deficit on time to flowering in photoperiod-insensitive genotypes. Exp Agric 32:13-28

Craufurd PQ, Qi A, Summerfield RJ, Ellis RH, Roberts EH (1996c) Development in cowpea (Vigna unguiculata). III. Effect of temperature and photoperiod on time to flowering in photoperiodsensitive genotypes. Exp Agric 32:29-40

Diaz BM, Muniz M, Barrios L, Fereres A (2007) Temperature thresholds and thermal requirements for development of Nasonovia ribisnigri (Hemiptera: Aphididae). Environ Entomol 36:681688. https://doi.org/10.1603/0046225X(2007)36[681:TTATR $\mathrm{F}] 2.0 . \mathrm{CO}$

Efron B, Hastie T (2016) Computer age statistical inference: algorithms, evidence, and data science. Cambridge University Press, New York

Efron B, Tibshirani RJ (1993) An introduction to the bootstrap. Chapman and Hall/CRC, New York

Eisler Z, Bartos I, Kertész J (2008) Fluctuation scaling in complex systems: Taylor's law and beyond. Adv Phys 57:89-142. https:// doi.org/10.1080/00018730801893043

Ellis RH, Covell S, Roberts EH, Summerfield RJ (1986) The influence of temperature on seed germination rate in grain legumes. II. Intraspecific variation in chickpea (Cicer arietinum L.) at constant temperatures. J Exp Bot 37:1503-1515. https://doi.org/10.1093/ $\mathrm{jxb} / 37.10 .1503$

Ellis RH, Simon G, Covell S (1987) The influence of temperature on seed germination rate in grain legumes. III. A comparison of five faba bean genotypes at constant temperatures using a new screening method. J Exp Bot 38:1033-1043. https://doi.org/10.1093/ $\mathrm{jxb} / 38.6 .1033$

Giometto A, Formentin M, Rinaldo A, Cohen JE, Maritan A (2015) Sample and population exponents of generalized Taylor's law. Proc Natl Acad Sci USA 112:7755-7760. https://doi.org/10.1073/ pnas. 1505882112

Ikemoto T (2003) Possible existence of a common temperature and a common duration of development among members of a taxonomic group of arthropods that underwent speciational adaptation to temperature. Appl Entomol Zool 38:487-492

Ikemoto T (2005) Intrinsic optimum temperature for development of insects and mites. Environ Entomol 34:1377-1387. https://doi. org/10.1603/0046-225X-34.6.1377

Ikemoto T (2008) Tropical malaria does not mean hot environments. J Med Entomol 45:963-969. https://doi. org/10.1603/0022-2585(2008)45[963:TMDNMH]2.0.CO;2

Ikemoto T, Egami C (2013) Mathematical elucidation of the Kaufmann effect based on the thermodynamic SSI model. Appl Entomol Zool 48:313-323. https://doi.org/10.1007/s13355-013-0190-6

Ikemoto T, Kurahashi I, Shi PJ (2013) Confidence interval of intrinsic optimum temperature estimated using thermodynamic SSI model. Insect Sci 40:240-248. https://doi.org/10.111 1/j.1744-7917.2012.01525.x

Jacobsen SE, Bach AP (2015) The influence of temperature on seed germination rate in quinoa (Chenopodium quinoa Willd.). Seed Sci Technol 26:515-523
Janzen DH (1976) Why bamboos wait so long to flower. Ann Rev Ecol Syst 7:347-391

Jarošík V, Honěk A, Dixon AFG (2002) Developmental rate isomorphy in insects and mites. Am Nat 160:497-510. https://doi. org/10.1086/342077

Jarošík V, Kratochvíl L, Honěk A, Dixon AFG (2004) A general rule for the dependence of developmental rate on temperature in ectothermic animals. Proc Biol Sci 271:S219-S221. https://doi. org/10.1098/rsbl.2003.0145

Jumrani K, Bhatia VS, Pandey GP (2017) Impact of elevated temperatures on specific leaf weight, stomatal density, photosynthesis and chlorophyll fluorescence in soybean. Photosynth Res 131:1-18. https://doi.org/10.1007/s11120-016-0326-y

Kilpatrick AM, Ives AR (2003) Species interactions can explain Taylor's power law for ecological time series. Nature 422:65-68

Kiritani K (2012) The lower development threshold temperature and the thermal constant in insects and mites in Japan (2nd edn). Mis Pub Natn Inst Agro-Environ Sci 31:1-74 (in Japanese with English abstract)

Kuang X, Parajulee MN, Shi P, Ge F, Xue F (2012) Testing the rate isomorphy hypothesis using five statistical methods. Insect Sci 19:121-128. https://doi.org/10.1111/j.1744-7917.2011.01428.x

Li D, Jackson RR (1996) How temperature affects development and reproduction in spiders: a review. J Therm Biol 21:245-274. https//:doi.org/10.1016/0306-4565(96)00009-5

Liese W, Köhl M (2015) Bamboo: the plant and its uses. Springer, Heidelberg

Lonati M, Moot DJ, Aceto P, Cavallero A, Lucas RJ (2009) Thermal time requirements for germination, emergence and seedling development of adventive legume and grass species. N Z Agric Res 52:17-29. https://doi.org/10.1080/00288230909510485

Martin TL, Huey RB (2008) Why "suboptimal" is optimal: Jensen's inequality and ectotherm thermal preferences. Am Nat 173:e102e118. https://doi.org/10.1086/527502

Mirhosseini MA, Fathipour Y, Reddy GVP (2017) Arthropod development's response to temperature: a review and new software for modeling. Ann Entomol Soc Am 110:507-520

Newman MEJ (2005) Power laws, Pareto distributions and Zipf's law. Contemp Phys 46:323-351

Oksanen L (2001) Logic of experiments in ecology: is pseudoreplication a pseudoissue? Oikos 94:27-38

Peacock JM (1975a) Temperature and leaf growth in Lolium perenne. I. The thermal microclimate: its measurement and relation to crop growth. J Appl Ecol 12:99-114. https://doi.org/10.2307/2401720

Peacock JM (1975b) Temperature and leaf growth in Lolium perrene. II. The site of temperature perception. J Appl Ecol 12:115-123. https://doi.org/10.2307/2401721

Peacock JM (1975c) Temperature and leaf growth in Lolium perenne. III. Factors affecting seasonal differences. J Appl Ecol 12:685697. https://doi.org/10.2307/2402182

Quinn BK (2017a) A critical review of the use and performance of different function types for modeling temperature-dependent development of arthropod larvae. J Therm Biol 63:65-77. https://doi. org/10.1016/j.jtherbio.2016.11.013

Quinn BK (2017b) Threshold temperatures for performance and survival of American lobster larvae: a review of current knowledge and implications to modeling impacts of climate change. Fish Res 186:383-396. https://doi.org/10.1016/j.fishres.2016.09.022

Quinn BK, Rochette R, Ouellet P, Sainte-Marie B (2013) Effect of temperature on development rate of larvae from cold-water American lobster (Homarus americanus). J Crustacean Biol 33:527-536. https://doi.org/10.1163/1937240X-00002150

R Core Team (2015) R: a language and environment for statistical computing. R Foundation for Statistical Computing, Vienna

Ratkowsky D (1990) Handbook of nonlinear regression models. Marcel Dekker, New York 
Ratkowsky DA, Reddy GVP (2017) Empirical model with excellent statistical properties for describing temperature-dependent developmental rates of insects and mites. Ann Entomol Soc Am 110:302-309. https://doi.org/10.1093/aesa/saw098

Ratkowsky DA, Olley J, Ross T (2005) Unifying temperature effects on the growth rate of bacteria and the stability of globular proteins. J Theor Biol 233:351-362

Rebaudo F, Struelens Q, Dangles O (2017) Modelling temperaturedependent development rate and phenology in arthropods: the devRate package for R. Methods Ecol Evol. https://doi. org/10.1111/2041-210X.12935 (in press)

Rodriguez JP, Jacobsen S-E, Sørensen M, Andreasen C (2016) Germination responses of Cañahua (Chenopodium pallidicaule Aellen) to temperature and sowing depth: a crop growing under extreme conditions. J Agro Crop Sci 202:542-553. https://doi.org/10.1111/ jac. 12158

Sandhu HS, Shi P, Kuang X, Xue F, Ge F (2011) Applications of the bootstrap to insect physiology. Fla Entomol 94:1036-1041

Schoolfield RM, Sharpe PJH, Magnuson CE (1981) Non-linear regression of biological temperature-dependent rate models based on absolute reaction—rate theory. J Theor Biol 88:719-731

Sharpe PJH, DeMichele DW (1977) Reaction kinetics of poikilotherm development. J Theor Biol 64:649-670

Shi P, Ge F (2010) A comparison of different thermal performance functions describing temperature-dependent development rates. J Therm Biol 35:225-231. https://doi.org/10.1016/j.jther bio.2010.05.005

Shi P, Ge F, Men X (2010) How to compare the lower developmental thresholds. Environ Entomol 39:2033-2038. https://doi. org/10.1603/EN10136

Shi P, Ikemoto T, Egami C, Sun Y, Ge F (2011) A modified program for estimating the parameters of the SSI model. Environ Entomol 40:462-469. https://doi.org/10.1603/EN10265

Shi P, Wang B, Ayres MP, Ge F, Zhong L, Li B-L (2012) Influence of temperature on the northern distribution limits of Scirpophaga incertulas Walker (Lepidoptera: Pyralidae) in China. J Therm Biol 37:130-137. https://doi.org/10.1016/j.jtherbio.2011.12.001

Shi P, Sandhu HS, Ge F (2013) Could the intrinsic rate of increase represent the fitness in terrestrial ectotherms? J Therm Biol 38:148151. https://doi.org/10.1016/j.jtherbio.2013.01.002

Shi PJ, Reddy GVP, Chen L, Ge F (2016a) Comparison of thermal performance equations in describing temperature-dependent developmental rates of insects: (I) empirical models. Ann Entomol Soc Am 109:211-215. https://doi.org/10.1093/aesa/sav121

Shi PJ, Sandhu HS, Reddy GVP (2016b) Dispersal distance determines the exponent of the spatial Taylor's power law. Ecol Model 335:48-53. https://doi.org/10.1016/j.ecolmodel.2016.05.008

Shi P, Chen Z, Reddy GVP, Hui C, Huang J, Xiao M (2017a) Timing of cherry tree blooming: contrasting effects of rising winter low temperatures and early spring temperatures. Agric For Meteorol 240-241:78-89. https://doi.org/10.1016/j.agrformet.2017.04.001

Shi PJ, Fan ML, Reddy GVP (2017b) Comparison of thermal performance equations in describing temperature-dependent developmental rates of insects: (III) phenological applications. Ann Entomol Soc Am 110:558-564. https://doi.org/10.1093/aesa/ sax063

Shi PJ, Ratkowsky DA, Wang NT, Li Y, Reddy GVP, Zhao L, Li BL (2017c) Comparison of five methods for parameter estimation under Taylor's power law. Ecol Complex 32:121-130. https://doi. org/10.1016/j.ecocom.2017.10.006

Shi PJ, Reddy GVP, Chen L, Ge F (2017d) Comparison of thermal performance equations in describing temperature-dependent developmental rates of insects: (II) two thermodynamic models. Ann Entomol Soc Am 110:113-120. https://doi.org/10.1093/aesa/ saw067

Taylor LR (1961) Aggregation, variance and the mean. Nature 189:732-735

Trudgill DL, Perry JN (1994) Thermal time and ecological strategiesa unifying hypothesis. Ann Appl Biol 125:521-532. https://doi. org/10.1111/j.1744-7348.1994.tb04989.x

Trudgill DL, Squire GR, Thompson K (2000) A thermal time basis for comparing the germination requirements of some British herbaceous plants. New Phytol 145:107-114

Ungerer MJ, Ayres MP, Lombardero MJ (1999) Climate and the northern distribution limits of Dendroctonus frontalis Zimmermann (Coleoptera: Scolytidae). J Biogeogr 26:1133-1145

Uvarov BP (1931) Insects and climate. Trans Entomol Soc 79:1-232

Wagner TL, Wu H-I, Sharpe PJH, Shcoolfield RM, Coulson RN (1984) Modelling insect development rates: a literature review and application of a biophysical model. Ann Entomol Soc Am 77:208-225

Watts WR (1971) Role of temperature in the regulation of leaf extension in Zea mays. Nature 229:46-47. https://doi.org/10.1038/229046a0

Watts WR (1972a) Leaf extension in Zea mays: I. leaf extension and water potential in relation to root-zone and air temperatures. J Exp Bot 23:704-712. https://doi.org/10.1093/jxb/23.3.704

Watts WR (1972b) Leaf extension in Zea mays. II. Leaf extension in response to independent variation of the temperature of the apical meristem of the air around the leaves, and of the root-zone. J Exp Bot 23:713-721. https://doi.org/10.1093/jxb/23.3.713

Watts WR (1973) Soil temperature and leaf expansion in Zea mays. Exp Agric 9:1-8. https://doi.org/10.1017/S0014479700023607

Watts WR (1974) Leaf extension in Zea mays: III. Field measurements of leaf extension in response to temperature and leaf water potential. J Exp Bot 25:1085-1096. https://doi.org/10.1093/ $\mathrm{jxb} / 25.6 .1085$

Xiao X, Locey KJ, White EP (2015) A process-independent explanation for the general form of Taylor's law. Am Nat 186:e51-e60. https://doi.org/10.1086/682050

Yamamoto T, Jinbo T, Hamasaki K (2017) Intrinsic optimum temperature for the development of decapod crustacean larvae based on a thermodynamic model. J Crustacean Biol 37:272-277. https:// doi.org/10.1093/jcbiol/rux016

Yin X, Kropff MJ, McLaren G, Visperas RM (1995) A nonlinear model for crop development as a function of temperature. Agric For Meteorol 77:1-16 